\title{
UNA REFLEXIÓN METODOLÓGICA, ONTOLÓGICA Y EPISTEMOLÓGICA DEL TRABAJO DE CAMPO EN UNA PRÁCTICA ESPIRITISTA POSMODERNA
}

Sara PASTOR-TALBOOM

UNED

spastor@palma.uned.es

\begin{abstract}
A METHODOLOGICAL, ONTOLOGICALAND EPISTEMOLOGICAL REFLEXION OF FIELD WORK IN A POSMODERN SPIRITISTA PRACTICE

Resumen: Este artículo tiene tres partes. En primer lugar presentamos las voces de algunos autores que se han caracterizado por su tratamiento de la espiritualidad, bien sea porque son más proclives al giro ontológico y a la empatía con el sujeto de investigación, un sujeto eminentemente espiritual, bien porque destacan su preferencia por la aproximación positivista. En segundo lugar se analiza un estudio de caso de la autora. Es el realizado en los Círculos de Ánima de una asociación originaria de Barcelona y que se ha extendido por Iberoamérica. Pretendemos hacer partícipe al lector de las tensiones que implica la observación participante en una práctica espiritista y que se revelan ante y desde la práctica académica e investigadora. Finalmente, se expone la disyuntiva entre 'flujo' y 'control' como el camino para entrar en la espiritualidad neoeriana, y la oscilación entre la creencia y la descreencia mientras dura la investigación.
\end{abstract}

Abstract: This article has three parts. First, we present the voices of some authors who have been characterized by their treatment of spirituality, either because they are more inclined to the ontological turn and empathy with the research subject, an eminently spiritual subject, or because they emphasize their preference for positivist approach. Secondly, a case study by the author is analyzed. It is the one carried out in the Círculos de Ánima [Circles of Anima] of an association originally from Barcelona and that has spread throughout Latin America. We intend to involve the reader in the tensions entailed in participant observation in a spiritualistic practice and which are revealed before and from academic and research practice. Finally, the dilemma between 'flow' and 'control' as the way to enter into New Age spirituality, as well as the oscillation between belief and disbelief along the investigation, are exposed.

Palabras clave: Observación participante. Imaginación. Seres espirituales. Círculos de Ánima. Antropología de la Muerte Participant observation. Imagination. Spiritual beings. Anima Circles. Anthropology of Death 
Nos cuentan López-Pavillard y Llera Blanes (2017) que el estudio y la investigación de las cuestiones espirituales, no necesariamente religiosas, implica una llamada de atención, un punto de reflexividad, acerca de la forma en que nos acercamos a ellas para conocerlas. Este es el motivo de este artículo.

Efectivamente, y siguiendo a estos autores, las metodologías, las ontologías y las epistemologías aplicadas en el amplio campo de las prácticas espirituales y abordadas desde el trabajo de campo antropológico pierden su certidumbre de la ciencia social clásica. Esto es particularmente pertinente cuando nos referimos a movimientos relacionados con la Nueva Era y/o el Neopaganismo, movimientos asociados a la polis posmoderna (Díaz Brenis, 2002)․․ Las metodologías implican pasar de la butaca a la observación participante, y de la observación participante a la experiencia participante y/o a la participación radical. En este sentido plantean el posible sentido y la utopía de 'tomarse en serio a los informantes' y eso del 'entendimiento profundo'. La otra cuestión, la que tiene que ver con la ontología, nos lleva a lidiar con la existencia de espíritus o energías, es decir, con la posibilidad o no de dar el giro ontológico. Y finalmente la cuestión epistemológica: dejamos atrás las creencias religiosas para ¿conocer? la espiritualidad. En este capítulo podríamos hablar de las experiencias personales del investigador, antropólogo en nuestro caso, de sus creencias o descreencias y del 'riesgo' de su conversión (López-Pavillard y Llera Blanes, 2017).

Estos estudios de lo 'invisible', que abarcan campos más recientes, como la antropología de la consciencia, suponen un reto para las ciencias sociales académicas (de las que tampoco se escapa la antropología a pesar de sus valores fundacionales como el relativismo cultural, véase metodológico, la huída del etnocentrismo y de los lugares comunes, y de versiones más modernas que plantean el problema de la cognición y cosmología en esta disciplina. Estamos pensando en Eduardo Viveiros de Castro (2013), Marisol de la Cadena (2015), Michel-Rolph Trouillot (2012), Philippe Descola (2005) y en la filósofa Isabelle Stengers (1997). Puede que nuestros esfuerzos no sean suficientes. En palabras de López-Pavillard y Llera Blanes:

Sin embargo, en la mayoría de los casos, estas antropologías [de la espiritualidad] se han presentado como 'traducciones', a través del lenguaje prototípico de la academia, de modelos exógenos hacia una epistemología hegemónica, donde se buscan lógicas 'entendibles' para un lector occidental ${ }^{2}$. Esas traducciones, a su vez, también esconden la vertiente utópica que involucra el proyecto espiritual, su voluntad de trascendencia y/o transformación. [...] Nos preocupa no solamente el estudio etnográfico de la espiritualidad, sino también los presupuestos y condicionantes - heurísticos, conceptuales, metodológicos, históricos, políticos, éticos - que determinan el estudio y la experiencia de la espiritualidad, y cómo ellos afectan o moldean un determinado tipo de conocimiento, entendimiento o experiencia sobre lo espiritual. (LópezPavillard y Llera Blanes, 2017, s. p.)

Tras esta introducción a la problemática son diversas las respuestas y posturas metodológicas que aportan e incorporan (en el sentido de embodiment) los distintos autores ${ }^{3}$. Podríamos citar en primer lugar algunos planteamientos de los que son más proclives al giro ontológico y a la empatía con el sujeto de investigación, un sujeto en nuestro caso eminentemente espiritual.

Es el caso de Manuela Cantón Delgado. Si bien en un primer momento sucumbió, como tantos otros, a las presiones de la academia, ahora agradecemos que nos haga partícipes de las experiencias que quedaron silenciadas por el camino. Así nos lo cuenta:

Veinte años atrás, durante mi trabajo de campo en Guatemala, me sometí a una sesión de "liberación de demonios" sobre la raída moqueta de un salón neopentecostal. Si Satanás era quien tejía "hilos en mis pies" y me ataba al mundo, sólo sacándolo de mi cuerpo podría sentir la acción del Espíritu. Al narrar este episodio para la que fue mi Tesis Doctoral, hubo mucho que silencié. La construcción del prestigio académico pasaba, y en gran medida continúa pasando, por blindarnos frente a la "sinrazón" -esa clase de racionalidad

\footnotetext{
1 Entendemos por modernidad la creencia en la ciencia, el progreso tecnológico, las metaexplicaciones racionales y el aumento de la secularización.

Por su parte, los posmodernos como grupos escatológicos "intentan dar repuesta alternativa y consoladora al vacío dejado por el paso de la modernidad" (Díaz Brenis, 2002, p.44). Se practica un reencantamiento del mundo, una conciliación de lo racional con lo místico, tras la percepción de una crisis en las ciencias como único medio para la explicación de la realidad. El aprovechamiento de los medios de comunicación como internet y redes sociales propias de un mundo globalizado y su inserción en áreas urbanas son otras de sus características. No obstante, a pesar de su reacción al capitalismo desalmado, no están exentos de caer en un mercado que los absorbe a través del consumo (entiéndase la venta de libros, múltiples cursos de formación o de terapia, seminarios, foros y demás eventos de reunión).

2 También, podríamos añadir, para un lector occidental ajeno a determinadas prácticas espirituales.

3 Aparte de manuales básicos de introducción a la etnografía y sus métodos de investigación como el de Martyn Hammersley y Paul Atkinson (2004).
} 
que se aparta de las premisas de la Ciencia. Esta exigencia en sí, base del Debate sobre la Racionalidad de los años sesenta, hace del trabajo de la antropología de la religión y la espiritualidad una tarea contradictoria y tensa, eventualmente hipócrita. Rescatando aquella experiencia sobre la moqueta y siguiendo a varios autores (Favret-Saada, Nils Bubandt y ciertas aportaciones de los ontólogos), sostengo aquí que la antropología de la religión y la espiritualidad no ha de plantearse la necesidad del giro ontológico: será girada o no será. No se trata de negar la epistemología a favor de la ontología, sino de conversar con seres invisibles que son metodológicamente reales, en tanto tienen efectos políticos. Eso significa que deben ser tomados en serio. El estudio de lo invisible no debería ser un obstáculo para quienes tratan habitualmente con nociones como identidad, imaginario, construcción ideológica o eficacia simbólica. Marcar distancia con las creencias o prácticas de los otros propone la tarea de desmentir definitivamente lo que Favret Saada llamó la Gran Distinción. Todo ello nos permitirá repensar la dicotomía postsecular religión/espiritualidad (¿reedición de la vieja dicotomía iglesia/secta? ¿coartada para ocuparnos de las creencias religiosas y las prácticas espirituales sin las asociaciones conservaduristas de la religión?) y dar paso a la participación radical, a la experiencia autoetnográfica, y al cuerpo como vehículo de conocimiento. (Cantón-Delgado, 2017, s. p.)

También lo es el de Edith Turner. Cuando la autora responde a la pregunta de qué situaciones espirituales han contado con su propia experiencia (Turner E. , 2003) narra un episodio en particular. La autora realiza una visita en 1985 a Zambia. Antes de ir procura mentalizarse, más que en ocasiones previas, con el objetivo de estar más cercana a la propia experiencia de los africanos (fuese lo que fuese aquello, ya que no sabía realmente qué experimentaban $)^{4}$. Su investigación en aquellos momentos se estaba desarrollando en el estudio de un ritual de sanación. Para su sorpresa, la sanación del segundo paciente culmina con la observación de la autora de una forma espiritual. Turner está implicada en el ritual mientras el doctor tradicional (sic) se inclina en medio de cánticos y toques de tambor para extraer el espíritu perjudicial: ve con sus propios ojos $^{5}$ una gran mancha gris de algo parecido a plasma emergiendo de la espalda de la mujer enferma. "Entonces supe que los africanos estaban en lo cierto. Hay cosas espirituales, hay aflicción espiritual: no es una cuestión de metáforas o símbolos, o incluso de psicología" (pág. 146, cursiva en el original). Y empieza a ver cómo los antropólogos han perpetuado una serie interminable de comentarios despectivos (put-downs en el original) sobre las numerosas situaciones espirituales en las cuales han participado, 'participado' en un sentido generoso. Turner cree que los etnógrafos podrían haber obtenido un material valioso, pero han estado operando con el paradigma equivocado: la negación de los positivistas, concretamente. Para alcanzar una máxima experiencia en un ritual "es realmente necesario que uno mismo se sumerja completamente en él” (pág. 146, traducción propia). Esto le permite alcanzar una cosmovisión (la nativa) totalmente diferente, ajena a la academia, capaz de reunir un material que de otra forma no podría haber sido informado.

Desde el campo de investigación de la historia de la ciencia destaca el reciente trabajo, editado en colaboración con otros autores, de Annette Mülberger. Los límites de la ciencia (Mülberger, 2016) hace explícito el auge, y el decaimiento posterior, del estudio científico del espiritismo, la mediumnidad, la clarividencia o la telepatía. En él se revisan los condicionantes socio-históricos que fundamentaron los criterios para establecer qué es científico y qué no lo es. Este recordatorio, ya que su análisis se centra a finales del siglo XIX y principios del XX, es muy pertinente porque nos hace ser conscientes, otra vez, de la construcción sociocultural (y por tanto histórica) de la que es objeto casi todo lo humano, como en nuestro caso la espiritualidad. En la reseña que realiza de este libro, Iván Sánchez- Moreno especifica que todos los autores "parten de una velada crítica contra los guardianes de la sacrosanta cientificidad de la psicología y otras disciplinas afines" así como cuestionan "la idiosincrasia fronteriza de lo que es legitimado por ciencia" (Sánchez-Moreno, 2016, p.565). Aunque también gozaron de apoyos, entre los ataques más feroces a los espiritistas estuvieron los realizados desde el ámbito médico, tachando las capacidades mediúmnicas de psicopatológicas. De hecho no fue casual que el fin de la hipnosis como herramienta científica coincidiera con el auge del sector farmacológico y auspiciado por la medicina.

Pasemos a explorar la visión opuesta: Brian Morris es harina de otro costal. En la Introducción de su obra Religión y antropología (Morris, 2009) el autor describe lo que para él son los siete enfoques teóricos del estudio de la religión ${ }^{6}$ :

1) Enfoques intelectualistas (Tylor, Frazer, Evans- Pritchard). La religión es vista como un medio de explicar el mundo. "El problema con este enfoque de la religión es que es sumamente parcial, y las explicaciones religiosas de los acontecimientos parecen muy poco plausibles cuando se las compara con las de la ciencia" (p. 12, cursiva añadida).

4 Aquí parece importante la predisposición del investigador, como veremos más adelante.

5 Es interesante la alusión a las propias percepciones, a los sentidos, como fuente de verdad 'inapelable'.

6 Aparte de las críticas que realiza al tratamiento posmoderno de la religión. Para conocer estas duras críticas véanse las pp. 17-19 de la obra citada. 
2) Enfoques emocionalistas (Malinowski, Freud, Wittgenstein, Spiro, Obeyesekere). La religión como alivio de temores y ansiedades.

3) Enfoques estructuralistas (Levi-Strauss, Godelier). La religión como sistema de comunicación cuya lógica simbólica y estructural de oposiciones binarias se busca revelar. Este enfoque "está divorciado de las realidades social y política" (p. 13).

4) Enfoques interpretativos (Geertz, Douglas, Sahlins, Beattie, Turner, Tambiah). La religión como sistema de significados y símbolos. Morris los clasifica como reacción a los antiguas explicaciones sociológicas de la religión propias del funcionalismo estructural y los critica ya que "han tendido cada vez más a repudiar la ciencia social y el análisis comparativo, y a adherirse a una metafísica bastante idealista, una metafísica antirrealista y que implica un relativismo epistemológico extremo" (p. 13, cursiva añadida).

5) Enfoques cognitivos (Boyer, Guthrie). La religión desde la sociobiología, el antropomorfismo (es decir, la atribución de características humanas a lo no humano) y la psicología pancultural.

6) Enfoques fenomenológicos (Otto, Jung, Eliade). La fenomenología, con la influencia de Husserl, comporta en palabras del autor "un método que intenta proporcionar una descripción neutral de la experiencia humana. Esto implica esencialmente dos pasos: primero, la noción de 'epojé' -la suspensión de juicios previos y la 'puesta entre paréntesis' de la 'actitud natural' [...]-, a fin de poderse concentrar puramente en la experiencia consciente, dejando que los 'fenómenos hablen por sí mismos'; y, segundo, la noción de 'intuición eidética', el descubrimiento mediante la intuición de la "esencia”" (p. 15). Las críticas de Morris a estos enfoques son prolijas: se hace de la cultura un fetiche; se reduce la vida social al lenguaje o los discursos y las creencias religiosas y las prácticas rituales a 'textos'; se postula un ámbito divino no como un constructo social sino como poseedor de una realidad ontológica; sostiene una epistemología individual empática y por tanto ignora la importancia de explicar la religión como un fenómeno social.

7) Enfoques sociológicos (Marx, Weber, Durkheim, Radcliffe-Brown, Firth, Godelier y Obeyesekere de nuevo, Gellner y el propio Morris). La religión es un constructo humano y debe ser vista en relación con la salud, el género, la identidad, la economía política, la globalización,... en definitiva, en su contexto sociocultural. Pero implica a su vez la comprensión empática de significados subjetivos o Verstehen. Esta es la visión de la religión más completa para el autor. Y, concretamente para el tema que nos ocupa, implica un agnosticismo metodológico:
"a los antropólogos que adoptan un enfoque sociológico no les preocupan ni el grado de verdad o la moralidad de los conceptos y creencias religiosos específicos, ni la autenticidad de las experiencias personales [...] Esto es debido a que, desde Durkheim, los antropólogos han distinguido explícitamente entre los temas relacionados con la existencia (la ontología), la verdad (la epistemología) y la moralidad (ética)- que no ha sido su preocupación principal- $y$ el papel del antropólogo en cuanto científico " (p. 20)

Como vemos, y aunque afirma en algún momento puntual que es necesario un enfoque integral (p. 21), se decanta claramente por el enfoque llamado "sociológico", es decir, aquél al que le preocupa la comprensión interpretativa o Verstehen de los hechos religiosos, pero sin olvidar nunca las relaciones estructurales que mantiene con el resto del todo social. Es decir, cree que el enfoque fenomenológico en sí no es suficiente (ya que se queda en la comprensión interpretativa solamente) y que por añadidura en sus versiones más radicales, véase posmodernistas o "posposmodernistas" (p. 19), deriva injustamente a una crítica feroz y oscura al enfoque sociológico y del método científico social, al repudio del conocimiento objetivo y de la ciencia empírica. Su preferencia por el método sociológico es clara, un enfoque con dos pilares y los dos igual de importantes: el materialista y socio-estructural por un lado, y el de la interpretación empática por otro.

Acabamos esta primera parte con el interesante ensayo de Joan Prat i Carós El estigma del extraño (2001). Después de hablarnos del 'principio de contaminación' de E. Burke Rochford (1985), es decir, del cuestionamiento que realiza el entorno del investigador de las relaciones que mantiene éste con los interlocutores de formas de vida disidentes al atribuírsele un estado de contaminación similar al que es aplicado a los sectarios, realiza una crítica a los peligros de un acercamiento excesivo al nativo religioso. En palabras del autor:

"La diferencia, pues, entre la pura observación y la observación participante es que, en la segunda, el investigador intenta vivir en el grupo asumiendo el riesgo de "convertirse en un nativo" [...] Pero el observador participante debe funcionar a otros niveles, ya que necesita estudiar, formular preguntas pertinentes y analizar los hechos desde una perspectiva antropológica. Si antes señalaba [...] que es un pobre observador de campo el incapaz de 
vivir momentos emocionalmente intensos con sus interlocutores, habría que añadir ahora que puede resultar también penoso el caso contrario: el de aquel que solo dedica sus esfuerzos a sentir las interacciones y las vivencias de los actos de plegaria o litúrgicos y es incapaz de analizar, críticamente, la información que aquellos vehiculan. [...]Veamos ahora el grado de implicación que cada autor ha considerado adecuado adoptar en su trabajo de campo. En principio, también aquí podríamos señalar la existencia de dos extremos con fases intermedias. Primeramente hallamos el tipo de implicación del investigador considerada "normal", es decir metodológicamente correcta, pues conserva la distinción entre lo que debe ser un investigador y un miembro [del grupo religioso disidente]. En el otro extremo estarían aquellos casos en los que las cotas de interrelación de los dos papeles son tan altas que la distinción resulta inviable" (Prat i Carós, 2001, pp. 97-98, cursivas añadidas).

Como podemos apreciar, la afinidad de Prat con la metodología de Meredith Mc Guire es notable. Siguiendo a esta autora (Mc Guire, 1982) resalta la importancia de distinguir la empatía con lo estudiado (lo que sí debe desarrollar el investigador y que consiste en comprensión, en la adopción de un punto de vista emic y en no creer sino hacer de la creencia un objeto de estudio neutral) de la simpatía (lo que no debe desarrollar el investigador y que implicaría una toma de posición de acuerdo con los estudiados). De ahí que según Prat no es extraño "que los estudios sociológicos y antropológicos sobre grupos religiosos concretos no suelen gustar a los sujetos que han proporcionado la información de base" (p. 102).

\section{Un estudio de caso}

La práctica espiritista que yo he estudiado son los Círculos de Ánima de una Asociación sin ánimo de lucro que llamaremos "A". Los Círculos se llaman así porque el ritual se conforma con el círculo de los participantes que, con manos entrelazadas, crean un 'tubo de luz' que conecta el centro de la Tierra con la fuente (el sol central del universo) y que permite que las almas en tránsito que lo deseen y estén preparadas asciendan a la luz. Los miembros de la asociación, que además presenta otras redes con sus respectivos círculos y que por las temáticas tratadas me permiten asociarla en gran medida con los movimientos New Age o Nueva Era, conciben por almas en tránsito aquellas que después de fallecer y pasadas 72 horas (lo que se entiende como un ciclo energético) no han ascendido ${ }^{7}$ a la luz.

Esta asociación nació en 2009 en Barcelona, España, y actualmente está extendida por el resto del estado y por varios países iberoamericanos. Que sea esta ciudad, Barcelona, no parece casual. Como muy bien han estudiado Gerard Horta (2004), Mònica Balltondre y Andrea Graus (2016), Barcelona y el ámbito catalán en general fueron desde la segunda mitad del siglo XIX ${ }^{8}$ hasta la década de los treinta del siglo XX, a consecuencia de la represión del régimen franquista, una región efervescente en modernidad, rebeliones proletarias y, también, en sociedades, librerías publicaciones y centros espiritistas. No obstante, el salto histórico no es una cuestión baladí: el espiritismo que tenemos entre manos ya no alude a mesas danzantes o giratorias ${ }^{9}$, ni siquiera a ouijas. La Nueva Era reclama una comunicación más diádica con las muertos, más a tono con el individualismo ${ }^{10}$, y desde luego no pertrechada en el temor sino en el 'Amor'.

Cabe reseñar que ha habido consentimiento informado por parte de la Asociación en cuanto a mi investigación. Y para mi sorpresa la respuesta ha sido en todo momento positiva e incluso proactiva ${ }^{11}$. Las técnicas utilizadas durante mi trabajo de campo han sido:

La observación y la observación participante en una veintena de Círculos, en algunos de los cuales se realizaron fotos, registros de audio y vídeos y donde tuve mi primera experiencia con los orbes ${ }^{12}$. Como nos recuerda Victor Turner (1980) una de las mayores ventajas de estas técnicas es permitir al investigador la percatación de posibles contradicciones entre lo que se hace, lo que se dice que se hace y lo que se dice que se debe hacer.

Historias de vida de la fundadora de A.y de las principales líderes (decimos las ya que el porcentaje de

\footnotetext{
7 Es interesante la alusión, no casual sino cultural, a la metáfora orientacional 'arriba es más, lo bueno, la virtud' (Lakoff y Johnson, 2009). De hecho, otra forma de caracterizar a estas almas es la de que 'vibran muy bajo'.

8 Resaltamos especialmente la fecha de 1888, año en el que se celebró en esta ciudad el Primer Congreso Espiritista Internacional coincidiendo justamente con la Exposición Universal.

9 Véase al respecto el trabajo de Guillaume Cuchet (2012).

10 Es la autonomía y la ausencia de jerarquía la que marca la ideología del Homo Aequalis (Dumont, 1987) y de la New Age (Carozzi, 1999).

11 La fundadora de la asociación tenía especial interés en saber si el resultado de mi investigación se iba a publicar y por tanto difundir al gran público.

12 Pequeñas esferas de luz en movimiento visibles con cámaras con flash y que, interpretadas como insectos minúsculos, gotas de agua o simplemente polvo por los positivistas, son en cambio para los neoerianos almas desencarnadas.
} 
mujeres en todos los niveles de la organización y participación ritual es significativa y siempre mayoritaria respecto a los hombres).

Entrevistas (abiertas y cerradas, formales e informales, buscadas y espontáneas), también en este caso a los organizadores de los Círculos de la red de Ánima como a los asistentes anónimos a las sesiones y en los lugares de realización de los rituales.

Grupos de discusión con los asistentes a los Círculos como con los inscritos en los cursos de formación ofertados por A.

Diario de campo. La mayor parte de las veces, ya que 'participaba' en los propios rituales de los Círculos como un asistente más, anotando los hechos horas después de haberlos observado y recurriendo por tanto a la memoria (soy consciente del papel limitador vs. evocador que puede tener este recurso). En las otras, es decir, en las de (¿simple?) observadora, tomando simultáneamente las notas en una esquina de la habitación. Nos hacemos eco de las palabras de Joan Prat sobre la utilidad del diario de campo "no sólo para recordar los hechos, sino también para descubrir el proceso personal de progresiva interacción con el grupo: hechos, experiencias, sensaciones, frases, gestos, escenas, impresiones, sonidos, olores, etc., que al principio resultan extraños al investigador y luego se hacen familiares, por lo que en muchos casos dejan de anotarse" (2001, p. 107).

Dada la abundante utilización de las redes sociales (páginas web, you tube, facebook, twitter, instagram) por parte de la asociación objeto de mi estudio, ha sido fundamental tener un acceso continuado y detallado de las mismas. Se ha realizado una búsqueda y lectura bibliográfica y webgráfica de los materiales relacionados con la investigación. Especialmente han sido objeto de análisis los archivos subidos tanto de mp3 como de mp4. Y particular atención ha requerido el canal de televisión Mindalia en el que también participa A.

Se ha estudiado la posibilidad no sólo de participar en las sesiones mensuales de tales Círculos (en Cataluña, base de la asociación, y Baleares fundamentalmente, pero también en otras partes de España e incluso de Sudamérica) sino de realizar los cursos ofertados al público (en este caso ha sido imprescindible el Curso de Ánima que habilita para poder crear un Círculo propio y ser su mediadora/canalizadora, como el Curso de Canalización ofertado por la propia fundadora de la asociación y que he creído fundamental para entender las bases de sus creencias).

Pasemos a continuación a relatar una de estas sesiones de Círculos de Ánima que obtuve mediante la observación no participante (en el sentido de no ser yo una de las integrantes del mismo) y que creo que permite al lector un acercamiento más detallado a la dinámica de un Círculo al permitirme tomar notas en el momento (más adelante analizaremos fragmentos de aquellas sesiones en las que mi observación sí fue participante, para descubrir las tensiones epistemológicas, ontológicas y fenomenológicas que se me revelaron ante y desde mi práctica académica e investigadora). Se trata de la que tuvo lugar el 2 de abril de 2017 al finalizar un curso de dos días titulado Regreso a la luz y que impartía la fundadora de A. con su pareja. El lugar fue una sala de considerable tamaño que se alquilaba para actividades grupales y también para terapias individuales en un barrio de Barcelona.

Después de pedir que se desconecten los móviles, todos los asistentes al círculo, incluídos la fundadora y su pareja, se sientan en sillas dispuestas en círculo. Suena una música relajante de fondo. Son 25 personas (incluida una niña de 8 años que ha acudido al curso con su madre porque desde hace aproximadamente un año ve personas que ya han fallecido) de fenotipo blanco, residentes en España, adultos pero de edades muy diversas, de clase media la mayoría y con estética similar y con mayor proporción de mujeres (17). Aproximadamente la mitad de los asistentes al curso y al círculo posterior tenían una fuerte vinculación personal con algún tipo de espiritualidad, de religiosidad no institucional, ya fuera en su tiempo de ocio o bien en su ámbito profesional. En el centro del círculo hay una planta, una vela, dos piedras de cristal (amatista y cuarzo ahumado $)^{13}$ y un vaso con agua. La idea es que estén presentes los cuatro elementos: tierra, agua, fuego y aire.

Se explica por parte de la fundadora, que actuará en el círculo como mediadora y canalizadora, que Ánima es un círculo de luz y de amor en el cual se realiza un trabajo en equipo, en unidad (unidad entendida como holismo, como la totalidad de la que se supone que venimos todos), que por medio de instrucciones canalizadas y la aportación de los asistentes se va a ayudar a las personas que al fallecer no encontraron el camino hacia la luz, y también a sus seres queridos que aún permanecen aquí (este aspecto terapéutico del círculo es muy interesante porque se da en sociedades urbanas e individualistas donde la práctica del duelo se ha reducido drásticamente, bien reprimiéndolo, bien medicándolo. Para una visión más desarrollada véase la obra de Louis-Vincent Thomas (1983). Colaborar en Ánima implica que cualquier ser en tránsito que esté aquí dispuesto a ser ayudado utilizará la conexión con cualquiera de los asistentes (si sienten una emoción repentina como tristeza, miedo, rabia o bien una frase en la 'cabeza' o incluso la sensación de que

13 Sabemos que para la New Age es muy importante la tipología y las potencialidades curativas de los cristales, entre otros. 
ser tocados por alguien) y en este caso será necesario comunicarlo al resto del Círculo. La comunicación es fundamental ya que, advierte, en caso de no ser así alguno de los asistentes se podría ir con un 'enganche', es decir, con la carga de un alma desencarnada de 'baja vibración'. De todas formas tranquiliza añadiendo que no hay que tener miedo porque son hermanos que necesitan ayuda: "no se trata de una sesión de espiritismo". Esta alusión de los otros como 'hermanos' nos recuerda a otros movimientos de la New Age como es la Hermandad Blanca.

Se le pide ayuda al arcángel Miguel. Es frecuente la utilización de una miríada de seres espirituales como ángeles y guías en los movimientos neoerianos. En el caso del arcángel Miguel éste ya no se quiere representar como un soldado con espada porque en la nueva era el amor es el sentimiento que se fomenta, y no la belicosidad. El arcángel Miguel permite no 'perderte' en la situación, a tener herramientas (que ellos llaman cuánticas) y ayudar a ese alguien. Por otro lado se solicita a los guías espirituales de cada quién que formen alrededor un círculo de luz que 'alimente' las auras individuales de manera que ninguna energía densa quede impregnada en ellas al finalizar la sesión.

Se empieza el ritual cerrando los ojos y cogiéndose las manos para que la energía fluya más fácilmente. Se inspira profundamente tres veces (no es casualidad el número tres, ya que junto con el 9, tres veces tres, son números significativos para los seguidores de la numerología). Se solicita el permiso de los 'guardianes del lugar' para realizar la ceremonia (el respeto a todos los seres, incluidos los fallecidos y habitantes del lugar en el que se realiza el ritual, es una norma muy acorde con el individualismo, la autonomía y el libre albedrío de la nueva tierra).

La fundadora canaliza las palabras del arcángel Miguel: "Amados hermanos, gracias por estar aquí. Vuestra labor realizada desde el corazón presenta una inestimable ayuda en pos de la luz". A continuación los asistentes se sueltan las manos. Tienen que imaginar ${ }^{14}$ que proyectan en el centro del círculo una columna de luz, blanca, brillante, que abarca todos los elementos que están dispuestos en el centro del círculo, y que conecta la tierra con el cielo, directamente con 'la fuente'. Se trata de que en este tubo de luz entren los seres en tránsito perdidos y que sean impulsados 'arriba' de manera 'natural', por la atracción que la luz va a realizar sobre sus almas. Una vez que entran en la luz deben mirar arriba y a la derecha ${ }^{15}$.

El Círculo se ha abierto. Se invita a los seres en tránsito que lo deseen vayan a la luz. Silencio. Respiraciones profundas. Prácticamente todos están con los ojos cerrados.

Empieza la primera intervención. Uno de los asistentes empieza a hablar en nombre de un alma en tránsito. Dice que fue asesinado y que por ello está resentido y enfadado. Tras una ligera confusión ya que hay varias personas que creen que pueden ayudarlo de forma divergente, y tras la resistencia de ascender a la luz, la pareja de la fundadora pone fin al 'debate' solicitando a esta alma que acuda a las puertas de Ávalon. Este Ávalon recuerda al Purgatorio cristiano ya que permitiría a las almas indecisas ir a un espacio de 'comprensión' custodiado por seres de luz, de alta vibración ${ }^{16}$. Para acceder a Ávalon, un lugar en la cuarta dimensión, 'entre el cielo y la tierra', es imprescindible que estas almas pidan ayuda (otro síntoma de respeto al libre albedrío individual).

A continuación habla otro asistente al círculo. Dice que ha conectado con un hombre que se llama Toni: "Estoy desesperado, hice algo horroroso, me amenazaron, si no lo hacía me iban a hacer cosas muy feas a mi familia. Yo hice lo que me pidieron. Yo os he escuchado pero no hay palabras para describir lo que llegué a hacer". "Dios es amor, confía", le dicen los participantes. Se solicita ayuda a los guías espirituales y asciende. A este respecto vale la pena reseñar que es realmente sorprendente la sensación de satisfacción que muestran los asistentes en sus caras: "el agradecimiento que los seres en tránsito te dan cuando entran en contacto con la luz es precioso. Porque desde el más profundo dolor de repente sienten la plenitud y siempre cuando se van te dan las 'gracias, gracias' con un amor inmenso".

Interviene una asistente en nombre de Rosa. Ha notado que Rosa quiere ponerse en contacto con ella porque ha empezado a sentir dolor en la parte izquierda de la espalda. Cada participante va añadiendo infor-

14 La acción de imaginar será uno de mis campos de batalla: tachada de 'irreal' desde una visión positivista y empírica, cercana a la academia, es para los neoerianos el medio que tienen las personas en esta dimensión (la tercera) para comunicarse con los seres más ascendidos (de la cuarta y quinta dimensión). En palabras de Morris:

la tradición esotérica concede también mucha importancia a la existencia de numerosas fuerzas espirituales -espíritus guía, ángeles, deidades- que actúan como intermediarios esenciales entre el devoto y la divinidad [...] Esto implica no sólo la postulación de un 'mundo de imágenes' [...] sino también el cultivo de una imaginación 'activa' o 'esotérica' (Sutcliffe, 1996, p.116). De manera que el contacto con el mundo de los espíritus, las deidades, los ángeles, los seres celestiales o los 'maestros ocultos' sólo se logra mediante el desarrollo de una 'consciencia analógica' y una 'visualización': la 'visión' o experimentación de vívidas imágenes mentales interpretadas como auténticos seres espirituales (Luhrmann, 1989, p.207). (Morris, 2009, pp. 371-372, cursiva añadida) 15 Podríamos preguntarnos con Robert Hertz el porqué de un hecho tan simple y tan universalmente arraigado como la preeminencia del lado derecho (Hertz, 1990).

16 Es interesante que la conexión con el portal etérico de Ávalon se realice en los monumentos megalíticos de Stonehenge y Avebury, circulares además, lo que permite establecer conexiones de este movimiento con la espiritualidad druidista y neopagana. 
mación según lo que cada uno percibe: unos imágenes, otros voces, otros frío/calor, otros dolores, tristeza o rabia. En este caso a Rosa le clavó una daga su madre. La madre también está y habla: "estaba loca, esquizofrénica, tu padre me hizo tanto daño, por favor hija, perdóname, te quiero hija". Aún así la participante protagonista dice que le sique pesando la 'daga'. Entonces la madre añade "así como te lo clavé, te lo desclavo, perdona”. Ahora 'Rosa' se siente mejor, pero aún así le pesa algo. Entonces se le recuerda los buenos momentos que pasó de pequeña con su madre ${ }^{17}$. Concretamente otra asistente comenta la muñeca que tenía y se la describe. La intervención acaba cuando la asistente que ha conectado con Rosa alza la mano y figura que le da la mano a la madre, "te perdono". Los asistentes dicen "se ha ido".

Ahora habla otro participante del círculo. Ve "un hombre negro, 'con ropas salvajes', flecha, que está muy enfadado porque era el cabeza de familia. Tiene las manos muy grandes"18. Y a continuación añade otro: "quiero vomitar y no puedo, no puedo moverme y casi no puedo respirar". Se solicita ayuda: luz violeta. Los baños de luz rosa o violeta se consideran herramientas cuánticas que permiten elevar la vibración (la frecuencia, la energía) de estas almas. Se le dice que arriba en la luz ya le está esperando su familia, concretamente se nombra un niño que viene a buscarlo. Todos los asistentes al Círculo coinciden en decir que se va a la luz y que dice "gracias". Es de nuevo ¿sorprendente? la simultaneidad.

A continuación aparece Carlos, un bebé que no llegó a nacer. El asistente que canaliza ha empezado a llorar. La fundadora, que ha tenido hasta ahora un papel más supervisor que interventor, invoca la luz arcoíris $^{19}$, y ella y su pareja comienzan a cantar una melodía sin letra, muy bonita por cierto (curiosamente la pareja de la fundadora participó en un programa televisivo de gran éxito por su voz). El asistente entre lágrimas ha abrazado al bebé y se ha ido a la luz. Los asistentes han visto "mucha luz".

Es el turno de 'Javier', que se siente muy triste y muy solo ya que nadie lo ve. También asciende.

C., una de las participantes del Círculo que más canaliza, se queja de que alguien le invade, de alguien que está sentado en su hombro izquierdo, también en sus piernas, y no se baja. La fundadora le insta a que se haga respetar, a que diga al ser que podemos ayudar siempre que no se invada nuestro espacio y no haga daño. A pesar de las imploraciones de C., la persona, que se presenta como Rafael, no le deja. Ante esta situación, la fundadora interviene de nuevo. Dice que el problema está en C., que al no tener una autoestima alta el ser lo percibe y se aprovecha. Por tanto dice en voz alta las palabras que debe repetir C.: "Rescato a la gran diosa ${ }^{20}$ que hay dentro de mí. Rafael, mis piernas son mías y sólo mías. Puedes comunicarte conmigo por telepatía". Una vez pasado el trance, la pareja de la fundadora dice que C. debe dar las gracias a Rafael por lo que le ha hecho comprender de ella misma.

La parte final del círculo está marcada por la edad de los seres y de los participantes. En primer lugar se presenta una niña de dos años pero que ya está en la luz: ha 'bajado' simplemente para presentarse a sus futuros padres. Se presenta como Alicia y dice que su madre se llama Alicia, como una de las asistentes. La fundadora dice que esto también puede ocurrir: que las almas de futuros hijos se pongan en contacto con sus futuros progenitores. En segundo lugar, es la niña de 8 años integrante del círculo la que dice haberse puesto en contacto con otra niña que se presenta como Lucía, de 6 años y rubia, que se quiere ir a la luz. Sorprende la naturalidad con la que la describe y la mira. Deciden enviarle una bola de luz rosa. "Se ha ido corriendo". Finalmente, y de forma improvisada, se integra en el círculo la hija de 7 años de la fundadora. Habla de una niña que ha muerto atropellada. De forma autónoma y bien aprendida de sus padres sabe lo que tiene que hacer y ella sola la 'manda' a la luz, "para que vaya con su madre".

Se cierra el Círculo. Ha durado aproximadamente dos horas. Para ello hay que imaginar y visualizar que el tubo de luz que se ha abierto al inicio se va cerrando hasta desaparecer. Y para asegurarse de que no queda abierta una puerta de acceso desde el 'Bajo Astral' se dibuja con la mano derecha una 'estrella de cierre', es decir, se traza un círculo en el aire y, dentro de él, una cruz y dos aspas con el mismo centro. Se coloca la palma de la mano sobre él y se dice "Este lugar queda cerrado al Astral". También se realiza sobre las cabezas para la energía individual ("Mi energía queda cerrada al Astral") y ante los espejos de la habitación si los hubiera, ya que se consideran portales energéticos. Ese cierre será momentáneo hasta que se abra un nuevo Círculo.

17 Se recomienda en estos casos que el alma recuerde los momentos de niñez. También es recurrente la invitación a que mire su 'luz interior'.

18 No se nos escapa el hecho de que es muy poco frecuente que aparezcan casos, que como éste, remitan a personas de otras culturas. Sí lo es más que pertenezcan a épocas 'pasadas'. En cualquier caso nunca he presenciado la imposibilidad de comunicación de los participantes con un alma en tránsito por problemas de 'idioma'.

19 Se cree que las almas de los bebés tienen una energía libre de karma y que presenta los colores del arcoíris, de ahí su nombre. Las alusiones a elementos de religiones orientales también son frecuentes y recuerdan la base teosófica del movimiento neoeriano. 20 Podemos apreciar con esta alusión a lo sagrado femenino una nueva conexión con el movimiento neopagano. No hay que olvidar que esta preeminencia de la 'mujer' también es palpable, no sólo en la proporción mayoritaria de mujeres asistentes a los círculos con respecto a los hombres, sino en las prácticas de 'womb blessing' o ‘bendición del útero' a las que son afines algunas de las coordinadoras de la Red de Ánima. 
Pasemos a continuación, como habíamos adelantado, a analizar algunas de las tensiones epistemológicas, ontológicas y fenomenológicas que se me revelaron ante y desde mi práctica académica e investigadora, de aquellas sesiones en las que mi observación fue participante.

Especialmente importante fue el primer Círculo en el que participé. Precisamente por eso sugerí si era posible el quedarme fuera del círculo para 'tomar notas', simplemente observando lo que allí acontecía. La respuesta fue contundente: a pesar de mis reticencias, y por qué no decirlo también, temores, la coordinadora dijo que la única forma correcta de estar en el círculo era tomando asiento entre ellos. Recuerdo mi tensión y el agotador viaje de ida y vuelta entre la más absoluta concentración para recordar todo lo que allí ocurría, y mi autollamada de atención para 'relajarme' y que el 'flujo' me permitiera, quizás, evocar lo que los demás veían.

Esa relajación fue, sin embargo, la tónica general en prácticamente todas las sesiones. Ni temor ni nervios. Pero tampoco nada más. Seguramente he esperado en más de una ocasión entrar en ese mundo de percepciones de algún tipo (visuales, táctiles, de oscilaciones térmicas...) que me permitieran saber ¿qué estaba en el camino correcto? Al comentar esta sensación con los demás asistentes en las 'puestas en común' tras la finalización del círculo, su interpretación era muy diferente a la mía. Insistían en que yo debía confiar en mis capacidades, y dejar atrás mis presunciones racionales. Efectivamente es frecuente la alusión en esta asociación a la disyuntiva entre 'mente' y ‘corazón' y, para estos casos, uno debe trabajar con el corazón ${ }^{21}$. El peso de mi mente, debido a mi experiencia vital de tradición académica, era demasiado grande. 'Yo' no me permitía ver con el corazón. De hecho, cuando compartía con ellos que 'me habían venido a la imaginación', cuando tenía los ojos cerrados, palabras o figuras (y que yo argumentaba por sugestión de lo que allí, en plena sesión, se exponía), ellos contraponían que no era tal imaginación, sino visualización. El énfasis en la necesidad de mi apertura a la canalización fue constante.

Hubo un caso de conato de 'apertura'. En un círculo me empecé a acordar de mi padre y de otros familiares fallecidos. La sensación fue agradable, de bienestar, de sentirlos 'cerca'. Al cabo de unos 15 minutos de iniciarse la sesión la mediadora del círculo me comunica que al lado mío hay un hombre, de mi familia. Que este hombre por la vibración que transmitía no era de tránsito sino de 'luz' y que me mandaba un mensaje: "está orgulloso de ti". No ocultaré el deseo que tuve de creer que aquello era real.

La sensación opuesta me produjo el 'encuentro' con $m i$ hijo adolescente en otra vida ${ }^{22}$. C., una de las participantes del Círculo más activas, dijo que sentía/veía una presencia que me llamaba pero que yo bloqueaba. C., que tenía los ojos cerrados todo el tiempo porque si no "no ve", me dijo a continuación "descruza las piernas" (yo las había cruzado hacía unos cinco minutos para cambiar un poco la postura, cosa que no hay que hacer porque dificulta el flujo de energía). Tras hacerlo, tanto ella como la mediadora vieron a un chico adolescente que identificaron como mi hijo en otra vida que se me presentaba para pedirme perdón. Por lo visto no se había portado bien conmigo. Se me instó, frente a mi rechazo inicial y mi incomodidad prácticamente durante todo el proceso de comunicación, a que le dijera en voz alta que le perdonaba. Ante la presión, aunque yo dije que no me acordaba de él y que por tanto yo percibía toda la situación como ajena a mí, se me sugirió que interpretara, tal cual una obra de teatro. Que le dijera "te perdono" "desde el corazón'. Tuve que repetirlo porque 'no salía creíble'. Se me sugirió que me imaginara que le abrazaba y así lo hice. En ese mismo momento C. empezó a respirar profundamente manifestando mucha alegría, sonriendo. Se me instó nuevamente a que continuara con la imaginación. Finalmente terminó el proceso con su subida hacia la luz, aunque yo tampoco pude sentirla. La sensación fue muy extraña. Al hablar del supuesto hijo de uno, aunque sea de otra vida (de hecho lo compararon para activar mis emociones de empatía con la hija que tengo 'en ésta') sentí una intrusión en la parcela que como investigadora una no quiere entrometer. Pero comprendí que formaba parte del paquete. Si bien yo accedía a retazos biográficos de los participantes, en ocasiones en temas tan peliagudos como contactos con sus hijos fallecidos antes de su nacimiento, yo ahora no era diferente, y no había motivo para no compartir con la excusa de que era mi intimidad (sintiera que ésta fuera, o no, real).

\section{La suspensión temporal de la descreencia}

Esta es la tesis defendida por Adam Klin-Oron, que a su vez toma de Elisabeth Shakman Hurd (2011), en su interesantísimo artículo sobre la experiencia que, como antropólogo, tuvo aprendiendo a canalizar en un curso New Age (Klin-Oron, 2014). En síntesis, no se trata de asumir, durante el proceso etnográfico,

\footnotetext{
21 Es precisamente estas alusiones a los diálogos y desde luego desencuentros entre 'mente' (raciocinio) y 'corazón' (sentimiento) de la asociación objeto de mi estudio las que me permiten categorizarla como práctica posmoderna.

$22 \mathrm{La}$ asociación, recordamos, cree en la reencarnación. El alma, es decir el espíritu, es inmortal, pero decide encarnarse en un cuerpo con su respectiva conciencia para vivir una experiencia vital que le permita aprender y evolucionar. Las encarnaciones y por tanto las vidas son múltiples, cada una de ellas con conciencias más elevadas o menos. De ahí las llamadas típicas de los movimientos neorianos al despertar de la Conciencia para que recuerde su propósito de vida: la ascensión evolutiva.
} 
permanentemente una nueva creencia sino de suspender temporalmente la descreencia. En este artículo el autor también confiesa la utilidad de la observación participante "activa" (p. 635) como herramienta para hacer el fenómeno estudiado más comprensible para él.

Una de las mayores dificultades que se encontró, y que igualmente he experimentado durante mi trabajo de campo, para 'entrar' en esa nueva manera de estar-en-el-mundo que proponen los neoerianos es la tensión entre flujo y control, es decir, practicar una técnica que implica una paradoja: por un lado fomentar la imaginación y desterrar las dudas (este es el flujo) y, al mismo tiempo, supervisar y dirigir el encuentro con las entidades (control). Este "flujo controlado" es un estado de conciencia en el cual la atención en uno mismo está maximizada pero la volición anulada (la canalización implica espontaneidad e inmediatez, sin pararse a discernir el contenido de un mensaje. La información es energía y la energía quiere fluir ininterrumpidamente). Al hacernos partícipes de unas de sus experiencias canalizadoras Klin-Oron dice: "estaba impresionado por mi habilidad para tener una conversación conmigo mismo sin que pareciera que sólo yo estaba hablando conmigo mismo" (p. 644, traducción propia). En su trabajo de investigación le ayudó sin duda ver que cuanto más practicaba (con ejercicios de meditación, con la respiración controlada, con la imaginación de luces y colores), más fenomenología sentía (emociones y sentimientos, sensaciones incorpóreas) y, concatenadamente, más epistemología alcanzaba.

En esta lucha no estamos solos. Contamos con varios autores como son Rebecca Seligman, Gananath Obeyesekere, Douglas Price-Williams y Tanya Luhrmann. Y de sus ideas: la disociación como la clave para esta nueva manera de estar-en-el-mundo (Seligman, 2008), lo que implica técnicamente el flujo controlado (Obeyesekere, 2012), la metáfora del flujo como el soñar despierto (Price-Williams, 1987) y la absorción como el modo en el que se tiene plena atención pero no intención (Luhrmann, 2005).

Al finalizar su trabajo de campo Klin-Oron suspende su suspensión de la descreencia. En ese momento confiesa que percibir a su guía espiritual como un ser presente tanto ontológica como epistemológicamente se le apareció como una opción viable. A pesar de que sus colegas profesionales y él mismo (p. 645) esperan de él un trabajo académico tras su investigación, y no que adopte una nueva espiritualidad, por un momento siente que la suspensión de la descreencia puede pasar a ser creencia. Siente que su observación participante podría girar las tornas hacia la conversión.

No obstante, a razón de sus motivaciones personales y profesionales, Klin-Oron vuelve a su anterior posición de estar en el mundo, frente al flujo controlado elige control:

[...] una brecha entre el mundo del investigador y el del sujeto de investigación permanecerá, quizás más cuando estamos hablando de fenómenos religiosos, en los cuales la creencia permanente y las prácticas recurrentes son usualmente el objetivo. Siempre pensé que la brecha era mi integridad profesional, pero ahora creo que es, de hecho, mi identidad personal -o, quizás, mi miedo a perderla. (Klin-Oron, 2014, p. 646, traducción propia).

No podemos dejar de estar de acuerdo.

\section{Bibliografía}

Balltondre, M. y Graus, A. (2016). The city of spirits: Spiritism, feminism and the secularization of urban spaces. En Hochadel, O. y Nieto-Galan, A., Barcelona: An Urban History of Science and Modernity, 1888-1929 (pp. 136-157). London and New York: Routledge.

Cantón-Delgado, M. (2017). Exorcismo, participación radical y subjetividades múltiples, Abstract para el Simposio Etnografiando prácticas espirituales del XIV Congreso de Antropología de la FAAEE, 5-8 de septiembre de 2017. Recuperado 24 mayo 2017 de http://congresoantropologiavalencia. com/comunicacion/exorcismo-participacion-radical-y-subjetividades-multiples/

Carozzi, M. J. (1999). La autonomía como religión: la nueva era. Alteridades , 9 (18), 19-38.

Cuchet, G. (2012). Les voix d'outre-tombe. Tables tournantes, spiritisme et société au XIX siècle. París: Éditions du Seuil.

De la Cadena, M. (2015). Earth Beings. Ecologies of Practice Across Andean Worlds. Durham: Duke University Press.

Descola, P. (2005). Las lanzas del crepúsculo. Relatos jíbaros, Alta Amazonía. Madrid: FCE.

Díaz Brenis, E. (2002). Nueva Era: una religión para la polis posmoderna. Boletín Oficial del INAH. Antropología (68), 44-49.

Dumont, L. (1987). Ensayos sobre el individualismo. Una perspectiva antropológica sobre la ideología moderna. Madrid: Alianza Editorial. 
Hammersley, M. y Atkinson, P. (2004). Etnografía. Métodos de investigación. Barcelona: Paidós Ibérica. Hertz, R. (1990). La muerte y la mano derecha. Madrid: Alianza Editorial.

Horta, G. (2004). Cos i revolució. L'espiritisme català o les paradoxes de la modernitat. Barcelona: Edicions de 1984.

Klin-Oron, A. (2014). How I learned to channel: Epistemology, phenomenology, and practice in a New Age Course. American Ethnologist, 41(4), 635-647.

Lakoff, G. y Johnson, M. (2009). Metáforas de la vida cotidiana. Madrid: Ediciones Cátedra.

López-Pavillard, S. y Llera Blanes, R. (2017). Simposio Etnografiando prácticas espirituales: sentido y compromiso frente a la utopía del XIV Congreso de Antropología de la FAAEE. Recuperado 23 mayo 2017 de http://congresoantropologiavalencia.com/simposiums/etnografiando-practicasespirituales-sentido-y-compromiso-frente-a-la-utopia/

Luhrmann, T. M. (1989). Persuasions of the Witch's Craft. Cambridge: MA: Harvard University Press.

Luhrmann, T. M. (2005). The Art of Hearing God: Absorption, Dissociation, and Contemporary American Spirituality. Spiritus 5, 133-157.

McGuire, M. (1982). Pentecostal Catholics: Power, Charisma and Order in a Religious Movement. Filadelfia: Temple University Press.

Morris, B. (2009). Religión y antropología. Una introducción crítica. Madrid: Akal.

Mülberger, A. (2016). Los límites de la ciencia: Espiritismo, hipnotismo y el estudio de los fenómenos paranormales (1850-1930). Madrid: Consejo Superior de Investigaciones Científicas (CSIC).

Obeyesekere, G. (2012). The Awakened Ones: Phenomenology of Visionary Experience. New York: Columbia University Press.

Prat i Carós, J. (2001). El estigma del extraño. Un ensayo antropológico sobre sectas religiosas. Barcelona: Ariel Antropología.

Price-Williams, D. (1987). The Waking Dream in Ethnographic Perspective. En Tedlock, B. (Ed.), Dreaming: Anthropological and Psychological Interpretations (pp.246-262). Cambridge: Cambridge University Press.

Rochford, E. B. (1985). Hare Krishna in America. Nueva Jersey: Rutgers University Press.

Sánchez-Moreno, I. (2016). Mente abierta vs. mente diseccionada: De cuando la ciencia vendió su alma. Revista de la Asociación Española de Neuropsiquiatría, 36(130), 565-569.

Seligman, R. (2008). Distress, Dissociation, and Embodied Experience: Reconsidering the Pathways to Mediumship and Mental Health. Ethos, 33(1), 71-99.

Shakman Hurd, E. (2011). A Suspension of (Dis)belief: The Secular-Religious Binary and the Study of International Relations. En Calhoun, C., Juergensmeyer, M. y VanAntwerpen, J. (Eds.), Rethinking Secularism (pp. 166-184). Oxford: Oxford University Press.

Stengers, I. (1997). Cosmopolitiques I et II. París: La Découverte.

Sutcliffe, R. (1996). Left Hand Path Ritual Magic. En Hardman, Ch. y Harvey, G. (Eds.), Pagan Pathways (pp. 109-137). Londres: Thorsons.

Thomas, L.-V. (1983). Antropología de la muerte. México: Fondo de Cultura Económica.

Trouillot, M.-R. (2012). Una historia impensable: la revolución haitiana como un no-evento. En Cañedo, M. y Marquina, A. (Eds.), Antropología política. Temas contemporáneos (pp. 351-396). Barcelona: Bellaterra.

Turner, E. (2003). The Reality of Spirits. En Harvey, G. (Ed.), Shamanism: A Reader (pp. 145-152). London: Routledge.

Turner, V. (1980). La selva de los símbolos. Madrid: Siglo Veintiuno Editores.

Viveiros de Castro, E. (2013). Perspectivismo y multinaturalismo en la América indígena. En Cañedo, M. (Ed.), Cosmopolíticas (pp. 417-456). Madrid: Trotta. 